\title{
Detailed Illustration of the Visual Field Representation along the Visual Pathway to the Primary Visual Cortex: A Graphical Summary
}

\author{
Simone Wärntges ${ }^{a, b}$, d Georg Michelson ${ }^{a-c}$ \\ ${ }^{a}$ Department of Ophthalmology, ${ }^{b}$ Interdisciplinary Center of Ophthalmologic Preventive Medicine and Imaging \\ (IZPI), and ' ${ }^{\mathrm{G}}$ raduate School in Advanced Optical Technologies (SAOT), University Erlangen-Nuremberg, Erlangen, and \\ ${ }^{\mathrm{d}}$ Center for Thrombosis and Hemostasis (CTH), University Medical Center Mainz, Mainz, Germany
}

\section{Key Words}

Visual pathway · Lateral geniculate nucleus - Primary visual cortex $\cdot$ Visual field $\cdot$ Optic nerve $\cdot$ Optic radiation

\begin{abstract}
Purpose: In the literature, different graphic illustrations are available, which depict different parts of the visual pathway in relation to visual field sectors, to retinal sectors, the layers of the lateral geniculate nucleus (LGN), or sections of the primary visual cortex (V1). However, a complete overview is missing, which may be useful for a more precise differentiation of predominantly ophthalmological from intracerebral diseases. It may also be of interest to investigate additional intracerebral reasons that are involved in impaired vision of largely unknown pathophysiology. Methods: This work combines the scientific knowledge of partial graphics in one detailed illustration that allows exact follow-up of the neuronal connections from individual visual field sectors to the $\mathrm{V} 1$ areas. A selective search for peer-reviewed graphics of the visual pathway was performed in PubMed and Google Pictures. Results: Sixteen different visual field sectors and their 16 corresponding retinal sectors were set in relation to 64 LGN sections and 20 areas of V1. Segmented cross-sectional
\end{abstract}

areas of the optic nerve supplemented the graphical representation of the fiber orientation in relation to the visual field. Conclusion: The detailed illustration of the visual field projection along the visual pathway structures may facilitate a more precise calculation of correlations between morphological and functional measurements of ophthalmological and neuroradiological examinations.

(c) 2013 S. Karger AG, Basel

\section{Introduction}

For some time now, in ophthalmology, the examination of intracerebral parts of the visual pathway by radiological imaging methods has become more and more important. Particularly, diffusion tensor imaging, which is based on magnetic resonance imaging (MRI), provides an interesting new option for the visualization and quantification of the third and fourth neuron of the visual pathway. The underlying tractographic technique reconstructs the fibers of the neuronal tracts [1]. Even fiber crossing of the optic chiasm may be visualized by this method [2]. Additionally, functional MRI allows the detection of localized activity, e.g. in the primary visual cor-

\section{KARGER}

E-Mail karger@karger.com

www.karger.com/ore
C 2013 S. Karger AG, Basel

0030-3747/14/0511-0037\$39.50/0
Simone Wärntges, MD

Center for Thrombosis and Hemostasis $(\mathrm{CTH})$

University Medical Center Mainz

Langenbeckstrasse 1, Bldg. 403, DE-55122 Mainz (Germany)

E-Mail Simone.Waerntges@ unimedizin-mainz.de 
tex (V1) in response to appropriate stimuli [3]. There are numerous ophthalmological methods to determine neuronal reasons for impaired vision $[4,5]$. Among them, we can find quantification (1) of the retinal nerve fiber layer (RNFL) thickness; (2) of the optic nerve head morphology; (3) of visual field defects by perimetry; (4) of the spatial-temporal contrast sensitivity, and (5) of the visual evoked potential. For an investigation of some glaucoma subtypes with incompletely elucidated pathophysiology (e.g. normal tension glaucoma, NTG), an interdisciplinary approach between ophthalmology and neuroradiology is desirable. A vascular dysregulation is discussed for NTG [6] and thereby, primary damage of the intracerebral part of the visual pathway may not be excluded [7-9]. Optic neuritis plays an important role for multiple sclerosis (MS) patients as well [10] and thus requires an interdisciplinary approach, too.

However, a complete overview of the fiber courses and their precise neuronal connections is needed to increase the diagnostic accuracy which is based on an interrelated evaluation of all these examination results. Many graphics providing parts of the visual pathway in detail have been published in the literature. However, to our best knowledge, a complete overview is missing. This work combines the published graphics to one complete illustration in order to facilitate detailed follow-up and calculations of the neuronal connections from individual visual field sectors to the respective V1 sectors, e.g. in ophthalmological studies, which apply neuroradiological examination methods.

\section{Method of Literature Search}

In this database study, a selective literature search was performed in PubMed (http://www.ncbi.nlm.nih.gov/pubmed/) and Google Pictures (http://www.google.de). Graphics published until October 2011 which contained the following key words were considered: 'visual field', 'visual pathway', 'optic nerve', 'lateral geniculate nucleus', 'optic radiation', and 'primary visual cortex'. In Google Pictures, 441 figures which included all key words were found. PubMed provided 8 publications which contained all key words. Only meaningful graphics of the visual pathway either from peer-reviewed articles or from internationally known textbooks (e.g. Netter's Neurology [11]) were selected. They represented the relationship either between individual visual field sectors and detailed anatomical structures of the visual pathway or between the anatomical structures themselves. References to articles in languages other than English, German, or French were excluded. The graphics regarded as eligible for further consideration were joined in one complete illustration. The main outcome measure was a detailed display of the neuronal connections in the lateral geniculate nucleus (LGN) and V1 in relation to visual field sectors.

\section{Results}

The composition of the visual pathway illustration (fig. 1) started with a display of the relation between a cross-section of $6 \mathrm{RNFL} /$ neuroretinal rim area regions (inferonasal, inferotemporal, temporal, superotemporal, superonasal, and nasal) and 6 corresponding visual field regions (superior, superonasal, nasal, inferonasal, inferior, and temporal) on each side [12]. The macular and nasal regions of the visual field were further subdivided into superior and inferior areas. The course of the retinal ganglion cell axons was projected on the visual field [13]. Next, information from a picture showing the cross-sectional areas of the third neuron anterior and posterior to the optic chiasm was added [14]. The cross-sections were adapted to the RNFL regions by supplementation of the macular, superior, and inferior part of the retina. Projection of the fibers to the respective layers of the LGN followed the graphical illustrations that were extracted from Netter's Neurology (chapter 3: 'Retina and optic nerve'; chapter 4: 'Optic chiasm, optic tract, lateral geniculate nucleus, and optic radiations', and chapter 5: 'Primary visual cortex') [11]. This drawing shows the 6 layers of the LGN. A separate image illustrates the LGN subdivisions in relation to the visual field sectors. Both detailed drawings were combined to one image and added to the illustration. Additionally, the magnocellular and parvocellular cell layers in the LGN were determined [15]. The fiber projection from the LGN or the visual field to the V1 completed the illustration [11]. The fibers were assigned to the anterior, central, and posterior bundle of the optic radiation in accordance with the visual field [16] and its pattern of visual field defects [17]. The resulting illustration consisted of 16 different visual field sectors, their 16 retinal sectors, 64 LGN sections, and 20 areas of V1.

\section{Discussion}

In the present work, one complete illustration was constructed from different published graphics that show parts of the visual pathway in relation to the visual field. The goal was to provide groundwork for the detailed assignment of individual RNFL sectors or visual field sectors to individual, reconstructed tracts of the third and fourth neuron of the visual pathway. The present scheme may be useful for the interpretation of MRI-based tractography of the visual pathway [1]. Also, the outline may be used for a more precise correlation of functional MRI
38

Ophthalmic Res 2014;51:37-41

DOI: $10.1159 / 000355464$
Wärntges/Michelson 
Fig. 1. Graphical illustration of the visual pathway from individual visual field sectors to V1 including cross-sectional areas. $\mathrm{B}=$ Blind spot $\mathrm{c}=$ contralateral fibers; $\mathrm{i}=$ ipsilateral fibers; I = inferior; Inf. = inferior calcarine area; IN = inferior nasal; IT = inferior temporal; $\mathrm{M}=$ area of the macula; $\mathrm{N}=$ nasal; $\mathrm{RGC}=$ retinal ganglion cell; $\mathrm{S}=$ superior; $\mathrm{SN}=$ superior nasal; $\mathrm{ST}=$ superior temporal; Sup. $=$ superior calcarine area; $\mathrm{T}=$ temporal.

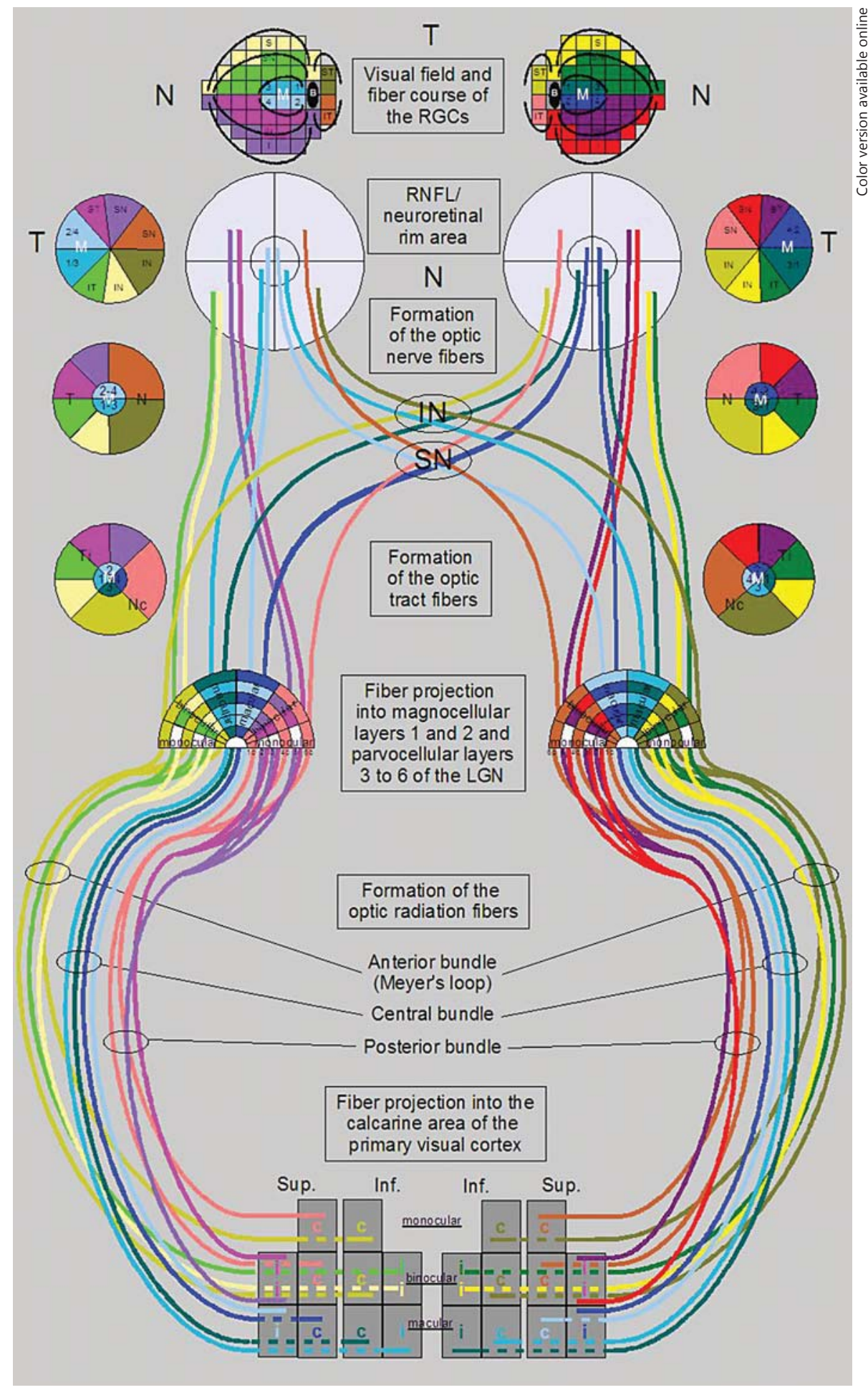

Ophthalmic Res 2014;51:37-41 DOI: $10.1159 / 000355464$ 
measurements in the LGN or V1 sectors with ophthalmological measurements in related studies.

The usefulness of the visual pathway scheme for the application in different specialties may become more obvious when considering relatively frequent diseases in neurology and ophthalmology. There are neurological diseases whose first symptom may occur in the visual system (e.g. optic neuritis in MS). On the other hand, apparent eye diseases like glaucoma may be influenced by perfusion disorders of the brain, as explained below.

There are numerous publications about optic neuritis in MS. The investigators have found that in MS, RNFL thickness measured by optical coherence tomography is associated with parenchymal fraction of the brain, cerebral fluid volume, and MS lesion volume [18-20]. RNFL thickness was also significantly correlated with fractional anisotropy and radial diffusivity of the connected contralateral optic radiation [21]. Additionally, RNFL thickness was considered to represent a better parameter for monitoring axonal damage longitudinally, whereas disease severity was best reflected by brain parenchymal fraction [22]. Even in normal appearing grey and white matter of MS patients, hotspots of tissue alterations may be detected with high specificity [23].

Whether small focal lesion processes in the brain are associated with a reduction in focal RNFL thickness is a question that is still unanswered. In glaucoma patients, a relationship was described between impaired visual function and resting blood perfusion within V1 [24]. The unequal cerebral blood flow in the ventral and dorsal V1 correlated with the differing visual function of the superior versus inferior visual field. The authors concluded that altered cerebral blood flow may contribute to glaucomatous optic neuropathy, or it may indicate glaucomatous neurodegeneration in the postretinal area caused by damage to the retinal ganglion cells [24]. Glaucoma without increased intraocular pressure (e.g. NTG) appears to be linked to Alzheimer's disease (AD). Some patients develop an AD-like perfusion pattern, but without clinical signs of AD. In those patients, the visual field defect progressed more rapidly than in NTG patients without an AD-like perfusion pattern [25]. In patients with CADASIL (cerebral autosomal dominant arteriopathy with subcortical infarcts and leukoencephalopathy), the retinal capillary flow may be mildly to moderately reduced [26]. Cerebral microangiopathy, also known as small vessel disease, appears in the form of cerebral white matter lesions (WMLs). The presence of WMLs is more likely associated with microvascular abnormalities of the retina than the absence of WMLs [27]. A primary vascular dys- regulation syndrome may be found in glaucoma patients. This syndrome leads to a mild reperfusion injury by an unstable ocular perfusion including blood flow reduction. In consequence, neural tissue is lost, glial cells are activated, and tissue will be remodeled [6].

All these examples substantiate a close collaboration between neurologists and ophthalmologists for the benefit of patients with diseases that cover the two specialties. These efforts may be supported by more precisely allocating small intracerebral lesions to special areas of the RNFL to confirm the causality of neuro(radio)logical and ophthalmological findings.

The differing degree of precision of the published graphics constituted a challenge for the composition of a preferably complete overview. Particularly, attention has been paid to conformity of functional with anatomical findings of the chosen graphics. In addition, the primary selection criterion was to extract graphics published in high-profile media. To our best knowledge, hitherto, a comparably complete scheme of the visual pathway connections has not been published.

When utilizing the present illustration, it has to be kept in mind that ophthalmological examinations often depict the right eye on the right side of the diagnosis form. In contrast, in neuroradiology, the right side of the brain is represented on the left side of the cross-sectional image. The missing agreement of side designations should be considered in correlation studies.

In conclusion, the complete illustration which summarizes functional and anatomical findings of the visual pathway may be helpful for interdisciplinary studies in ophthalmology and neuroradiology in order to evaluate the acquired data in more detail. The intention of the work is an educational one.

\section{Acknowledgement}

This study was supported by the Federal Ministry of Education and Research (BMBF), Bonn, Germany (excellence cluster Medical Valley EMN, Grant MVEMN-A-02).

\section{Disclosure Statement}

The authors report no conflicts of interest. The authors alone are responsible for the content and writing of the paper.
Wärntges/Michelson 


\section{References}

1 Hofer S, Karaus A, Frahm J: Reconstruction and dissection of the entire human visual pathway using diffusion tensor MRI. Front Neuroanat 2010;4:15.

2 Wedeen VJ, Wang RP, Schmahmann JD, Benner T, Tseng WY, Dai G, Pandya DN, et al: Diffusion spectrum magnetic resonance imaging (DSI) tractography of crossing fibers. Neuroimage 2008;41:1267-1277.

3 Zhang N, Zhu XH, Zhang Y, Park JK, Chen W: High-resolution fMRI mapping of ocular dominance layers in cat lateral geniculate nucleus. Neuroimage 2010;50:1456-1463.

4 Jampel HD, Singh K, Lin SC, Chen TC, Francis BA, Hodapp E, et al: Assessment of visual function in glaucoma: a report by the American Academy of Ophthalmology. Ophthalmology 2011;118:986-1002.

5 Lin SC, Singh K, Jampel HD, Hodapp EA, Smith SD, Francis BA, et al, American Academy of Ophthalmology, Ophthalmic Technology Assessment Committee Glaucoma Panel: Optic nerve head and retinal nerve fiber layer analysis: a report by the American Academy of Ophthalmology. Ophthalmology 2007;114:1937-1949.

6 Flammer J, Mozaffarieh M: What is the present pathogenetic concept of glaucomatous optic neuropathy? Surv Ophthalmol 2007; 52(suppl 2):S162-S173.

7 Michelson G, Wärntges S, Engelhorn T, El Rafei A, Hornegger J, Dörfler A: Integrity/demyelination of the optic radiation, morphology of the optic nerve head, and contrast sensitivity in glaucoma patients. [Integrität/Demyelinisierung der Radiatio optica, Morphologie der Papille und Kontrastsensitivität bei Glaukompatienten.] Klin Monbl Augenheilkd 2012;229:143-148.

8 Michelson G, Engelhorn T, Wärntges S, El Rafei A, Hornegger J, Doerfler A: DTI parameters of axonal integrity and demyelination of the optic radiation correlate with glaucoma indices. Graefes Arch Clin Exp Ophthalmol 2013;251:243-253.

9 Michelson G, Wärntges S, Engelhorn T, El Rafei A, Hornegger J, Doerfler A: Cluster analysis of glaucoma patients using the retinal nerve fiber layer thickness of the optic nerve and DTI parameters of the optic radiation. J Clin Exp Ophthalmol 2011, DOI: 10.4172/21559570.S4-001.
10 Kolbe SC, Marriott M, Walt A, Fielding J, Klistorner A, Mitchell PJ, Butzkueven H, Kilpatrick TJ, Egan GF: Diffusion tensor imaging correlates of visual impairment in multiple sclerosis and chronic optic neuritis. Invest Ophthalmol Vis Sci 2012;53:825-832.

11 Royden Jones H: Netter's Neurology. http:// www.netterimages.com/ product/ 9781929007066/ (accessed October 25, 2011).

12 Bowd C, Zangwill LM, Medeiros FA, Tavares IM, Hoffmann EM, Bourne RR, et al: Structure-function relationships using confocal scanning laser ophthalmoscopy, optical coherence tomography, and scanning laser polarimetry. Invest Ophthalmol Vis Sci 2006;47: 2889-2895.

13 International Task Force on Ophthalmic Education of Medical Students on Behalf of the International Council of Ophthalmology (ICO): Ophthalmic education: principles and guidelines of a curriculum for ophthalmic education of medical students: contributors and contents. 2010. http://archive. icoph.org/med/index.html (accessed October 25, 2011).

14 Walsh TJ: Visual Fields: Examination and Interpretation, ed 2. Oxford, American Academy of Ophthalmology, 1996.

15 Meissirel C, Wikler KC, Chalupa LM, Rakic P: Early divergence of magnocellular and parvocellular functional subsystems in the embryonic primate visual system. Proc Natl Acad Sci USA 1997;94:5900-5905.

16 Yamamoto T, Yamada K, Nishimura T, Kinoshita S: Tractography to depict three layers of visual field trajectories to the calcarine gyri. Am J Ophthalmol 2005;140:781785.

17 Augustin AJ: Augenheilkunde, ed 2. Berlin, Heidelberg, New York, Springer, 2001.

18 Gordon-Lipkin E, Chodkowski B, Reich DS, Smith SA, Pulicken M, Balcer LJ, Frohman EM, Cutter G, Calabresi PA: Retinal nerve fiber layer is associated with brain atrophy in multiple sclerosis. Neurology 2007;69:16031609.

19 Siger M, Dziegielewski K, Jasek L, Bieniek M, Nicpan A, Nawrocki J, Selmaj K: Optical coherence tomography in multiple sclerosis: thickness of the retinal nerve fiber layer as a potential measure of axonal loss and brain atrophy. J Neurol 2008;255:1555-1560.
20 Zimmermann $\mathrm{H}$, Freing A, Kaufhold $\mathrm{F}$, Gaede G, Bohn E, Bock M, Oberwahrenbrock T, Young KL, Dörr J, Wuerfel JT, Schippling S, Paul F, Brandt AU: Optic neuritis interferes with optical coherence tomography and magnetic resonance imaging correlations. Mult Scler 2013;19:443-450.

21 Reich DS, Smith SA, Gordon-Lipkin EM, Ozturk A, Caffo BS, Balcer LJ, Calabresi PA: Damage to the optic radiation in multiple sclerosis is associated with retinal injury and visual disability. Arch Neurol 2009;66:9981006.

22 Dörr J, Wernecke KD, Bock M, Gaede G, Wuerfel JT, Pfueller CF, Bellmann-Strobl J, Freing A, Brandt AU, Friedemann P: Association of retinal and macular damage with brain atrophy in multiple sclerosis. PLoS One 2011; 6:e18132.

23 Weygandt M, Hackmack K, Pfüller C, Bellmann-Strobl J, Paul F, Zipp F, Haynes JD: MRI pattern recognition in multiple sclerosis normal-appearing brain areas. PLoS One 2011;6:e21138.

24 Duncan RO, Sample PA, Bowd C, Weinreb RN, Zangwill LM: Arterial spin labeling fMRI measurements of decreased blood flow in primary visual cortex correlates with decreased visual function in human glaucoma. Vision Res 2012;60:51-60.

25 Sugiyama T, Utsunomiya K, Ota H, Ogura Y, Narabayashi I, Ikeda T: Comparative study of cerebral blood flow in patients with normaltension glaucoma and control subjects. Am J Ophthalmol 2006;141:394-396.

26 Harju M, Tuominen S, Summanen P, Viitanen M, Pöyhönen M, Nikoskelainen E, Kalimo H, Kivelä T: Scanning laser Doppler flowmetry shows reduced retinal capillary blood flow in CADASIL. Stroke 2004;35: 2449-2452.

27 Wong TY, Klein R, Sharrett AR, Couper DJ, Klein BE, Liao DP, Hubbard LD, Mosley TH, Investigators ARIC: Atherosclerosis Risk in Communities Study. Cerebral white matter lesions, retinopathy, and incident clinical stroke. JAMA 2002;288:67-74.
Detailed Illustration of the Visual Field Representation
Ophthalmic Res 2014;51:37-41 DOI: $10.1159 / 000355464$ 